\title{
ETHICAL CONCERNS ABOUT THE ONLINE SALE OF INSTRUCTOR-ONLY TEXTBOOK RESOURCES
}

\author{
Arline Savage and Mark G. Simkin
}

\begin{abstract}
Yes, your test bank and solutions manual are for sale and it is very easy for students to acquire them. Using a stakeholder framework, we analyze the ethical issues involved in acquiring, using, and distributing these instructional resources by individuals besides the professors for whom they are intended. We also discuss countermeasures that stakeholders might use to deal with this latest development.
\end{abstract}

At State University, the weaker students in a particular auditing class did so well on their first multiple-choice examination that the professor became suspicious. Investigating, he learned that one of his students also worked in the school's continuing education department, and (with the help of his publisher) discovered that someone there had downloaded not only the test bank and solutions manual for his auditing course, but also instructional materials for alternate courses in marketing, law, and finance. Responding to what he had learned, the professor carefully composed his final exam to include a mix of 
questions - some from the test bank, and some he wrote himself. Sure enough, the suspected students received nearly perfect marks on the test-bank questions, but scored near the bottom of the class on the alternate questions, leaving little doubt about what had happened (Bishop, 2006). ${ }^{1}$

In today's electronic age, both students and faculty enjoy many benefits of using digital media, including the ability to create and distribute instructional materials via email, administer tests online, communicate in real time, and teach entire courses electronically to students residing in remote locations. Given the widespread popularity of these applications, it is perhaps not surprising that new types of instructional abuses have also emerged, including the employment of online "mills" to ghost-write term papers, the posting of examination answers by the students in one class for the benefit of the students in another class, and even the text messaging of test answers while an exam is in progress.

The (true) scenario above describes one of the newest and, to date, leastrecognized types of activity - the unauthorized acquisition and distribution of test-bank questions and similar instructional materials that typically accompany most modern accounting textbooks. But how easy is it to obtain such materials, and what ethical and legal concerns are involved with a student using them?

The objectives of our inquiry were to determine how easy it is for students to obtain such restricted materials as test banks and solutions manuals, discuss the ethical issues involved in the availability of these materials, and investigate what countermeasures are available to the major stakeholders in this matter. The next section of this paper examines our "ease-ofacquisition" question in greater detail, while the following section discusses some of the ethical issues involved in this matter. The third section discusses countermeasures to deal with this development, while the last section of this paper summarizes our findings and provides conclusions.

\section{HOW EASY IS IT TO ACQUIRE INSTRUCTIONAL MATERIALS ONLINE?}

It is easy to dismiss the threats described in our initial story as circumstantial - that is, an unusual situation in which an auditing student happened to also work for an alternate division of the university and was therefore in a unique position to access instructional materials from the publisher. But control weaknesses are control weaknesses, and the 
conditions of this story are probably not uncommon. Our scenario also begs the question "how easy is it to obtain the test bank and/or solutions manual to popular accounting textbooks?"

In a word, we found that the answer is "very." Perhaps the most straightforward way to obtain restricted instructional materials online is to assume the identity of a legitimate professor and communicate via email with the publisher. Once the publisher recognizes the "professor" as a legitimate book adopter, it usually gives him or her access to the Instructor portion of its Web site, and therefore any of the materials it contains, including the power point slides, the solutions manual to end-of-chapter questions, and of course, the test-bank questions for the book. The authors' experience ${ }^{2}$ in this matter confirms that most publishers do not contact professors directly.

Assuming the identity of someone else is a brazen and illegal act, and also, it turns out, an unnecessary one. An alternate approach is to simply purchase the desired materials through one of the several online vendors. To investigate this possibility, the authors searched the Internet for possible online sources, and quickly found a plethora of online suppliers, all of whom were selling these materials to willing buyers. We found that StudentDump.com was a particularly rich source of vendors and that its home page contained postings for a wide variety of solutions-manuals, test-banks, and similar instructional materials. Fig. 1 provides a list of textbooks for accounting subjects, and is only a partial list of the total test banks and/or solutions manuals available from one seller. Many popular textbooks are listed here.

A product or service that seems to be for sale on the Internet does not necessarily mean that it actually is for sale. For this reason, one of the authors also attempted to purchase several test banks from advertising sellers, using the name of her pet dog as the name of the buyer. Alter paying the price of $\$ 79.95$ via Paypal (she was asked by the seller not to mention the word "test bank" in the Paypal transaction), she almost immediately received a zip file via email containing the full test bank for the most recent edition of a popular intermediate financial accounting textbook. In a second experiment, this same author was also successful in purchasing the test bank and the solutions manual for that same text book for the bargain price of $\$ 10$ each from another seller on craigslist.com. These were emailed to her in pdf format. Once again, she was required to remit the purchase price via Paypal. Finally, the author was successful in purchasing a third test bank - a hard copy that was offered for sale on StudentDump.com and that was mailed to her by an online bookseller from Indiana.

These three experiments lead us to conclude that, at least as of this writing, it is remarkably easy to obtain the test banks and solutions manuals 
Accounting for Governmental and Nonprofit Entities, 14, Wilson, Kattelus, Reck Accounting Information Systems, 10, Romney, Steinbart

Accounting Information Systems, 11, Ronmey, Steinbart

Accounting Information Systems, 5, James A. Hall

Accounting Information Systems, 6 James A. Hall

Accounting Information Systems, 7, Gelinas, Dul]

Accounting Information Systems A Business Process: Approach, 2, Jones. Rama

Accounting Principles, 7, Weygandt, Kieso, Kimmel

Accounting Principles, 8, Weygandt, Kieso. Kimmel

Accounting Principles, 9, Weygandt

Advanced Accounting, 10, Beams, Clement, Anthony, Lowensohn

Advanced Accounting. 10. Fischer, Taylor, Cheng

Advanced Accounting, 2, Jeter, Chaney

Advanced Accounting, 3, Jeter, Chaney

Advanced Accounting, 8, Hoyle, Schaefer, Doupnik

Advanced Accounting, 9, Beams, Clement, Anthony, Lowensohn

Advanced Accounting, 9, Fischer, Taylor, Cheng

Advanced Accounting, 9, Hoyle, Schaefer, Doupnik

Financial Accounting,6,Harrison, Horngren

Financial and Managerial Accounting, 13, Williams, Haka, Bettner

Financial Management: Theory \& Practice, 12,Brigham, Ehrhardt

Financial Reporting and Analysis, 10, Charles H. Gibson

Financial Reporting and Analysis, 11, Gibson

Intermediate Accounting, 12,Kieso, Weygandt, Warfield

Intermediate Accounting,4,Spiceland, Sepe, Tomassini

Intermediate Accounting, Kieso, Weygandt, Warfield

Intermediate Accounting Revised, 4,Spiceland, Sepe, Tomassini

Intermediate Accounting, FASB Update, 12, Donald E. Kieso

Managerial Accounting, 11, Garrison, Noreen, Brewer

Managerial Accounting, 12, Garrison, Noreen. Brewer

Modern Advanced Accounting, 0, Larsen

Fig. I. Examples of Solutions Manuals and Test Banks for Accounting Textbooks

Available from Sellers Advertising on StudentDump.com

to leading academic textbooks in general, and to accounting textbooks in particular. Moreover, our own purchasing experiences suggest that, with a little comparative shopping, such purchases can be relatively inexpensive.

\section{THE ETHICS OF ACQUIRING AND USING UNAUTHORIZED TEST BANKS AND SOLUTIONS MANUALS}

The sale of test banks and/or solutions manuals in an open market involves both legal and ethical issues. For example, third-party vendors who sell testbank materials to others would appear to be violating copyright law. 
However, in this paper, we focus on the ethical side of such sales and provide some arguments and concerns about the subject.

Ethical issues are often best addressed within a formal framework. Since the concept of utilitarianism was introduced by John Stuart Mills in 1861 . the evaluation of the end results of an action has been an accepted approach in assessing decisions (i.e., the decision to sell instructor resources to the general public) and resulting actions (Brooks, 2004, p. 310). Although several frameworks are available to perform this task, the authors chose the "stakeholder framework" outlined in Brooks (2004) for their analysis. Stakeholder theory considers the interests of groups or individuals who are affected by the conduct of a business. The rationale for using the stakeholder framework in Brooks (2004) is that it is particularly appropriate for analyzing this issue. For our investigation, this framework requires an ethical analysis of how each key stakeholder group is impacted by the decision to engage in the business of acquiring and selling those textbook resources developed exclusively for instructors.

To analyze the sale of restricted instructional resources to the general public, we identified the following key stakeholders: (1) the publishers who own the copyrights to the materials in question; (2) the individuals or companies who sell these materials on the open market; (3) the instructional institutions which students attend; (4) both knowledgeable and unaware students; (5) university instructors; and (6) the accounting profession itself. How might each of these stakeholders be affected by this matter? We examine each in turn.

\section{Publishers}

Publishers ${ }^{3}$ expend valuable resources in developing instructional materials for their books - both directly in out-of-pocket costs, and indirectly in protecting and distributing these materials to legitimate users. It also seems clear that such ancillary instructional resources as test banks and solutions manuals make textbooks more attractive to potential adopters. When Internet vendors compromise the security of these instructional materials, they also negatively impact the suitability of the related textbook for classroom use. This directly impacts the profitability of publishers and infringes on copyright and possibly trade secret laws.

We recognize that at least some publishers are aware of this problem and are now using various countermeasures to solve it. We discuss these in the penultimate section of this article. For a variety of reasons, however, 
a publisher might choose not to pursue such courses of action - for example, the publisher might provide test-bank resources to a questionable requester to reduce the risk of losing a potential book adoption. Fig. 1 suggests that many of them probably have accommodated requests from illegitimate sources. One illegitimate acquisition and sale of a computer file copy of a test bank could result in the proliferation of the availability of that material to students because of ease of distribution via the Internet.

\section{Sellers}

When one of the authors first attempted to buy a test bank from a thirdparty vendor using her own name, the order was first accepted but subsequently cancelled because "the test bank was no longer available." Subsequent orders were placed using her dog's name, and these orders were quickly and successfully executed. For the most expensive purchase (\$79.95), we know that the payment was in turn forwarded to a "Non-U.S. Verified Premier Member" of Paypal, indicating that the sale of U.S. test banks has become an international business.

The authors' opinion is that test-bank and solutions-manual sellers are engaged in unethical and illegal behavior - and they seem to know it. For example, one seller requested that the author did not mention the term "test bank" when paying the invoice. Simply stated, such vendors are selling the intellectual, copyrighted property of others for personal gain. In doing so, they violate widely known copyright laws, regardless of whether they claim they were 'not aware' that such materials were copyrighted. Indeed, because copyright infringement is considered a strict liability offense in the United States, ignorance of the law is no excuse.

\section{Educational Institutions}

There are many reasons why the ethics of acquiring and using test banks might be of interest to university instructors in general, and to businessschool faculty in particular (Verschoor, 2007; Davy, Kincaid, Smith, \& Trawick, 2007). In light of recent scandals (Enron, Worldcom, etc.), educational institutions in general, and colleges of business in particular, have become particularly sensitive to the ethical orientation of their students (e.g., McCabe, Butterfield, \& Trevino, 2006). Thus, one reason to worry about student access to online instructional resources is this increased 
sensitivity to ethical behavior in the workplace. Some business schools are responding by strengthening their coverage of "ethics" in student coursework, and even screening students on the basis of the applicant's ethical disposition (Harker, 2005).

A second reason why colleges of business might be concerned about such student behavior is the growing amount of empirical evidence that questionable behavior is more likely to be a problem in business schools than elsewhere (Klein, Levenburg, McKendall, \& Mothersell, 2007; Iyer \& Eastman, 2006; McCabe, 1997; McCabe et al., 2006). ${ }^{4}$ In a study of cheating at 16 schools, for example, McCabe (1997) found that $84 \%$ of business students self-reported at least one incidence of serious cheating in the past year, compared to $72 \%$ for engineering students and $66 \%$ for all the students in that sample. McCabe et al. (2006) found a similar result in a recent study of graduate students, with over $56 \%$ of graduate business students reporting incidences of cheating or related questionable behavior compared to $47 \%$ for nonbusiness students.

Studies of student cheating often rely on self-reported statistics - a practice that ensures anonymity but, at the same time, makes statistical interpretation problematic. The empirical evidence suggests that, if anything, the averages computed from studies using self-reported data are likely to be low. One reason for the direction of this bias is the simple fact that some students are uncomfortable reporting any such behavior - for example, because they fear discovery. Another reason to believe the statistics are low is new empirical evidence that many students do not fully understand what constitutes "cheating," and actually report higher incidences of it after exposure to explicit definitions of cheating behavior (Burns, McGoldrick, \& Schubmann. 2007).

\section{Students}

For students, the decision to buy instructional materials raises both legal and ethical issues. Although they may not be aware of the legalities involved, students who purchase test-bank or solutions-manual materials on the Internet are accessing restricted, and often stolen, intellectual property usually to obtain better grades. As a result, such students are engaging in an illegal activity, even though they might perceive this act as having less negative consequences than the purchase of physical stolen goods. Students are also unlikely to be moved by the economic losses that publishers, who are often perceived as overcharging students for textbooks, might suffer 
(Macgregor, 2007; Marcus, 2006; Student Public Interest Research Group, 2009). Other factors that may influence the decision to make such purchases are the ease of engaging in the act and the low potential for getting caught (Lathrop \& Foss, 2000).

From an ethical perspective, many students might not define "acquiring and using a test bank" as unethical or "cheating." One counter argument from students may be that, in most western societies, citizens can do anything that is not expressly defined as illegal. If faculty members do not explicitly forbid such behavior in their syllabi, using a test bank as a study aide is an example of such an act. It is also possible to argue that students are not aware that they are buying copyrighted materials, and are therefore making a decision based on needs rather than legal concerns.

Historically, students have always had access to a host of resources to help them perform well on homework and in-class examinations - if they wished. Early examples included practice tests, outside readings placed on reserve at the local library, and class tutors. Most of these can also be described as "sanctioned resources" - aides that most professors approve or even encourage. But not all such resources are this way. For example, in the past, fraternities and sororities have been well-known repositories of tests spanning a wide range of courses at the local university, all neatly filed by subject area and instructor - a resource not widely available to all students in a given class and therefore of concern to the faculty using old or only partially modified tests in their classes.

Then too, students can argue that they acquired their instructional materials through publicly available sources of which instructors are (or should be) aware, and that they are therefore free to use such information anyway they like. For example, a number of Web sites now provide approved online test questions from past certification examinations such as the GMAT (see Lavelle, 2008), and students regularly employ them to prepare for such tests. Presuming faculty knowledge about such sites, a logical conclusion is therefore that a student would be foolish to not avail himself or herself of such a resource, in much the same way that a student would be foolish to skip a review session before an examination or ignore important supplementary reading material likely to be germane to a test.

Finally, students who purchase test banks might claim that such an act does not necessarily guarantee them a better grade on the test. Such an argument is bolstered by the fact that they have no prior knowledge of what questions will actually be on a forthcoming examination, and are therefore merely using these materials to prepare for it. To the extent that this behavior could be classified as "studying," students might even argue 
that they were doing exactly what was expected of them - preparing for an examination in an efficient manner - and that instructors should be happy for this result.

It also occurs to us that only those students with access to, and the financial means to acquire, test banks or solutions manuals are likely to make or embrace such arguments. In accordance with Brooks' (2004, p. 317) discussion of Fairness Among Stakeholders, a faculty member's decision to do nothing about the matter is only fair if such a decision "is seen to be lair to all stakeholders." Those students without such materials are not likely to agree with the equity of this do-nothing decision.

\section{Instructors}

There are several reasons why instructors might care about online testbank purchases. In most universities of which the authors are aware, for example, professional conduct requires instructors to maintain a "level playing field" that equitably and impartially assesses student mastery of course materials and allows all students to compete equally for their grades. Those instructors who rely on publisher-provided test banks and/or collect end-of-chapter problems need to know that such materials may be and probably are - available for sale. But if all students do not know about the availability of such restricted instructional materials, or cannot afford them, some students would seem to enjoy an unfair advantage when completing homework assignments or taking tests based on such items. Ironically, this problem is particularly burdensome to those instructors who base their adoption decisions in part on the very pedagogical support that now appears to be compromised by test-bank and solutions-manual sellers.

Some accounting instructors are also textbook writers who augment their teaching earnings with the royalties from book sales. Authors are usually not paid royalties on the test banks and solutions manuals that accompany their books because such ancillary materials are typically given freely as inducements to potential book adopters. However, it seems possible to us that access to the test banks and solutions manuals for class textbooks might depress textbook sales and therefore negatively affect author royalties. After all, why should those students focused on grades buy an expensive textbook when they already have access to all the graded materials from those books? In this sense, we think that authors might lose royalties as a result of the Internet sale of instructional resources. 


\section{The Accounting Profession}

Finally, it seems clear to us that the accounting profession itself might be interested in the unauthorized sale of test banks and solutions materials. One reason for this is that the market for test-bank questions might also include the answers to the questions to certification tests as well - a matter of immediate concern to those responsible for developing and administering such examinations (Musthaler, 2008; Hoazempa, 2008). Another reason is the importance that the profession now places on the education and practice of ethical behavior - an emphasis that, to us, contrasts sharply with Internet purchases of test banks and other professor-only resources. This seems especially important if the purchases are made by students who know their actions are illegal or immoral (as opposed to purchases by students who lack such knowledge and recognition). The potential implications for employees, especially accountants and auditors, should be of grave concern, particularly given that Lawson (2004), for example, finds that (1) such employees best understand how to circumvent internal controls and (2) research suggests that there is a close connection between cheating in college and the workplace (Lawson, 2004).

Yet a third reason why the accounting profession might be interested in the sale of instructional materials is the fact that its members depend on the integrity of the grades that students earn in accounting classes as unbiased measures of the relative strength of candidates competing for unfilled accounting positions. Those students who have purchased test banks or perhaps used solutions manuals to help them answer end-ofchapter questions, thwart this objective, and their good grades might give false signals about their competency on the job.

Finally, the profession might be interested in the unauthorized sale of instructional materials because they violate important copyright laws. These laws vary from country to country, with weaker protection for copyright owners in some countries than in others. For example, the International Intellectual Property Alliance (IIPA) recently submitted its 2009 Report on Copyright Piracy in 48 Countries to the U.S. Trade Representative. The IIPA represents the U.S. copyright-based industries, which include over 1,900 U.S. companies producing and distributing materials protected by copyright laws throughout the world. The report expresses member concerns with the explosive growth of online copyright infringements, documents how widespread copyright infringement problems are, and recommends that 13 countries be placed on the Priority Watch List in 2009 (Argentina, Brunei, Canada, Chile, Egypt, India, Indonesia, Mexico, 
Pakistan, China, the Philippines, Russia, and Thailand). Consequently, copyright infringement in these countries is less risky than in the United States, but does not change the fact that test banks and solutions manuals for college-level textbooks are no longer confidential materials.

\section{COUNTERMEASURES}

It is easy to guess that neither publishers nor university instructors would agree with vendor or student arguments that justify the sale or purchase of test-bank or solutions-manual materials. What countermeasures are available to each of the major stakeholders in this issue? We examine some possibilities for each group separately.

\section{Internet Vendors and Publishers}

Internet vendors would seem to have little incentive to participate in countermeasure activities. Indeed, their profitability derives from test-bank sales and agreeing to forego such activities means putting themselves out of business.

Because "publishers" are directly affected by test-bank sellers, they have an economic motive to actively pursue them. At least some publishers are aware of this problem and are now using various countermeasures to solve it. At Cengage (formerly Thomson publishing), for example, solutions to some end-of-chapter problems are now web-based and dynamic, meaning that the system automatically offers solutions with new starting values to solve generic problems. Similarly, publisher Wiley now employs a lawyer devoted exclusively to identifying and disrupting online test-bank sellers.

Finally, to protect instructional resources, publishers may also find it necessary to more-thoroughly authenticate future requests for instructoronly materials. For example, this may entail personal phone calls to instructor-requesters, department-chair verifications, limiting distributions to hard-copy versions, or requiring written confirmations before sending materials - all of which are likely to require additional time and effort for publishers and instructors as well as drive up the price of new textbooks to students. 


\section{Educational Institutions}

There is much that an educational institution can do in this matter. One countermeasure is to ensure that faculty members are aware of the widespread availability of restricted instructional materials - for example, by distributing information about this matter in official university emails or posting such information on campus Web sites. Another countermeasure is to adopt campus-wide policies that specifically forbid the use of such materials in student honor codes. Finally, offices of student affairs can develop consistent sanctions for students caught using such materials.

To deter student use of restricted materials, universities can also make students more aware of the adverse publicity that usually accompanies cheating violations (Coyne, Massey, $\&$ Thibodeau, 2005). At one institution, for example, the students who were caught cheating also had their GMAT scores cancelled, thus derailing their careers (Lavelle, 2008). Again, such penalty tactics would seem to work best where university honor codes explicitly identify the use of test banks or solutions manuals as "cheating," but might be less effective where either no university-wide policy exists or instructional syllabi do not explicitly forbid it.

\section{Students}

It is unfair to students for some to have access to instructional materials while others do not. At least some students have motive to disrupt the use of test banks or similar instructional materials - especially if they are disadvantaged when others use them. In addition, many university honor codes require students to report the cheating behavior of others - yet another incentive for educational institutions to adopt official policies about such usage. Both such countermeasures require an informed student body, however.

\section{Instructors}

To us, an important element of quality delivery of relevant material is that instructors provide all students with an equal chance in taking a given test or completing end-of-chapter homework assignments. This enhances the accuracy and reliability of student grades. The availability of test-bank 
questions or solutions to such assignments impedes this objective, especially if instructors are not aware of it or if only some students have them.

In order to level the playing field for all students, instructors could post instructor-only materials on campus Web sites or place them on reserve in the library. However, given that test-bank questions and solutions manuals are copyrighted materials, either measure could potentially compromise the protection of such materials and could, therefore, be considered inappropriate. An alternate option of including an explicit statement on syllabi that "acquiring or using such materials is considered a form of cheating" might be better, but of course does not guarantee compliance. Nonetheless, because students often do not know that a given activity is unethical, such a countermeasure is useful because it can increase student awareness of unethical behavior in general and the use of unauthorized test banks and solutions manuals in particular. In addition to including explicit statements on syllabi, we also recommend developing and disseminating campus-wide policies and student honor codes.

For instructors, perhaps the most obvious solution to this problem is to simply not use publisher-supplied test-bank questions or count homework that utilizes end-of-chapter assignments. Alternates include creating new multiple-choice questions for objective tests or developing original constructed-response questions that more-deeply probe student mastery of the underlying subject matter. Examples include using student debates, business memorandums, in-class discussions, presentations, and professor-developed projects, simulations or cases such as those published in accounting journals.

Although straightforward, we realize that these countermeasures are also burdensome to faculty - especially to adjunct faculty who do not teach accounting courses on a regular basis. Further, we are unaware of institutions of higher learning that reward faculty for such efforts. However, the use of test-bank or similar assessment materials that we now know can be acquired externally and so easily does not seem like much of an option either.

Similar to educational institutions, an additional alternative available to faculty members is to impose penalties or sanctions on students who use test banks without permission, or to at least call student attention to the potentially negative publicity attendant with such usage. We also note that it might be difficult for faculty members to prove that students possessed forbidden test banks or solution manuals, and that the incremental work involved might not be worth the efforts even if it were possible.

Finally, instructors who are also authors may have an additional, economic incentive (relative to those who are nonauthors) to combat the sale of their instructional resources. These individuals can also monitor 
Internet offers to illegally sell these resources by regularly checking Web sites like StudentDump.com and inform publishers or other authorities of their findings. We suspect that this, in turn, would pressure publishers to investigate and hopefully disrupt such sales.

\section{The Accounting Profession}

Because the accounting profession is also a stakeholder in test-bank sales, it too can become more active in adopting countermeasures to disrupt them. One possibility is to explicitly identify such behavior as unacceptable in professional codes of conduct. Another possibility is to actively protect its own professional test questions from unauthorized distribution. Yet a third avenue is to work closely with universities in seeking other remedial actions - for example, by distributing information about such activities to those instructors who are also members of professional organizations.

\section{SUMMARY AND CONCLUSIONS}

In this paper, we have used the term "instructor-only resources" to refer to materials such as test banks and solutions manuals that publishers typically provide to textbook adopters free of charge. Recently, we found that these restricted resources are now available for sale on the Internet and worse, that it is very easy to acquire test banks and/or solutions manuals to most of the major accounting books now in use.

To the extent that copyright and trade secret laws protect such instructional resources from unauthorized third-party sales, the primary responsibility for protecting such intellectual property would appear to rest with the publishers. But as long as the laws of supply and demand are in effect, it is difficult for us to imagine how such sales can be totally thwarted - especially from international suppliers. Although publishers have the most immediate economic stake in the matter, placing the onus of responsibility on them, for example by demanding tighter controls over access to such test banks, may not (in the authors' opinion) be the most realistic option. In particular, we believe that additional restrictions on the access to test banks and solution manuals are more likely to inconvenience instructors and perhaps drive up the market price of test banks or solutions manuals (because they will be more difficult to obtain), rather than stop their sales. 
As suggested in the foregoing discussions, there is much that publishers, educational institutions, professional accounting organizations, and even students can do to thwart the sale or use of test banks on the Internet. For instructors, perhaps the most obvious countermeasure to the widespread sales of test banks and solutions materials is to avoid using them when constructing examinations or assigning graded homework. We realize that this is a time consuming and perhaps unrewarding alternative, and not a happy one for accounting teachers. We also encourage universities to identify the purchase of instructor-only materials as unacceptable behavior in student codes of conduct and the accounting profession at large to become more active in thwarting Internet sales of such products.

\section{NOTES}

1. The authors recognize that the higher scores on the questions drawn from the test bank may also have reflected students' mastery of the underlying subject material. The issue remains that this occurred by the unauthorized use of the instructor's test bank.

2. We have checked this with a number of colleagues, whose experiences coincide with ours.

3. The publisher stakeholder group includes sales representatives and employees whose economic benefits derive from the success of the publishing firm.

4. A limitation of this research is that the quoted citations do not control for social desirability response bias when other ethics research recommends doing so (e.g., Bernandi \& Guptill, 2008).

\section{REFERENCES}

Bernandi. R. A., \& Guptill, S. T. (2008). Social desirability response bias, gender, and factors influencing organizational commitment: An international reply. Journal of Business Ethics, 81, 797-809.

Bishop, T. J. F. (2006). Fraud in the audit class. Internal Auditor, 63(February), 95-99.

Brooks, L. J. (2004). Business \& professional ethics for directors, executives, \& accountoms (3rd ed.). Mason, OH: Thomson South-Western.

Burns, R. T., McGoldrick, K. M., \& Schubmann, P. W. (2007). Self reports of student cheating: Does a definition of cheating matter? Journal of Economic Education, 38, 3-16.

Coyne, M. P., Massey, D. W., \& Thibodeau, J. C. (2005). Raising students ethical sensitivity with a value relevance approach. Advances in Accounting Education: Teaching and Curriculum Innovations, 7, 171-205.

Davy, J. A., Kincaid, J. F., Smith, K. J., \& Trawick, M. A. (2007). An examination of the role of attitudinal characteristics and motivation on the cheating behavior of business students. Ethics and Behavior, 17, 281-302. 
Harker, P. (2005). Cheating: The new epidemic. Global Agenda, 3, 193-194.

Hoazempa, B. (2008). A threat to your career: Combating certification fraud. Certification Magazine, 10(September), 36-39.

Iyer, R. \& Eastman, J. K. (2006). Academic dishonest: Are business students different from other college students? Journal of Education for Business, 82(November; December), $101-110$.

Klein, H. A., Levenburg, N. M., McKendall, M., \& Mothersell. W. (2007). Cheating during the college years: How do business students compare? Journal of Business Ethics, 72. 97-206.

Lathrop, A., \& Foss, K. (2000). Student cheating and plagiarism in the Internet era: A wake up call. Englewood, $\mathrm{CO}$ : Libraries Unlimited.

Lavelle, L. (2008). GMAT cheating controversy grows. Business Week Online, June 30, p. 13.

Lawson, R. A. (2004). Is classroom cheating related to business students' propensity to cheat in the 'Real World'? Journal of Business Ethics, 49, 180-199.

Macgregor, R. (2007). Mad over prices, students refuse to go buy book. The Globe and Mail. September 17 , p. A2.

Marcus, J. (2006). US rage at textbook price hike. Times Higher Education Supplement 0. August 11, p. 11

McCabe, D. L. (1997). Classroom cheating among natural science and engineering majors. Sicience \& Engineering Eihics, 3, 433-445.

McCabe, D. L., Butterfield, K. D., \& Trevino, L. K. (2006). Academic dishonesty in graduate business programs: Prevalence, causes, and proposed action. Academy' of Management Leaning and Education, 5(September), 294-305.

Musthaler, L. (2008). Cheaters: Inside the hidden world of IT certification fraud. Network World, 25(September 1), 38-40.

Student Public Interest Research Group. (2009). Campaign to Reduce College Textbook Costs. Available at MakeTextbooksAffordable org. Retrieved April 17.

Verschoor, C. C. (2007). Who is responsible for college students cheating? Strategic Finance. July 15-16, p. 61 .

\section{APPENDIX. DISCUSSION QUESTIONS AND SUGGESTED ANSWERS}

1. Question: The article identified six major stakeholders involving the online sale of test banks and solutions manuals. Who are they, and what do you think the majority in each stakeholder group would feel about this matter?

Answer: (1) Publishers: against, (2) sellers: for, (3) educational institutions: against, (4) students: can be for or against, (5) instructors: probably against, and (6) the accounting profession: against. 
2. Question: Can you identify any additional stakeholders besides those you have listed in question 1?

Answer: Employers such as CPA firms would probably be concerned about this matter. As stated in the article, many employers use the course grades students have earned in school to help them evaluate the relative strengths and weaknesses of job applicants. Grades that come from a student's familiarity with testing materials, rather than the underlying knowledge on which such grades are based, obstruct this metric.

Another possible stakeholder is the parents of the students who buy instructional materials online. In many cases, such parents help students pay for their child's college education, not college efforts to avoid acquiring such an education. It is also easy to imagine that the parents of students on full scholarships might have deep feelings about their child's purchase of such materials - especially if the instructor or educational institution pursued disciplinary action against the student or the parents themselves were affected by adverse publicity stemming from a student's actions.

3. Question: The president of your university asks you to be the student representative on a committee to consider adopting a policy on online purchases of instructor resources by students. Using the views of the major stakeholders other than students, list at least three justifications for, and three ethical arguments against, buying these resources.

Answer: Justifications for allowing students to purchase instructor resources include:

1. Permitting such purchases helps sellers make money.

2. In some countries, selling these materials is not illegal.

3. As a practical matter, it is difficult to deny student purchases of Internet resources.

4. Allowing test-bank purchases encourages the competitive spirit in students - an important characteristic in modern business.

Arguments against a policy that allows students to purchase instructor resources:

1. The sale of instructor resources infringes on copyright laws; students are therefore purchasing illegal goods. 
2. Not all students are aware of the availability of, or can afford, these materials; students obtaining the materials have an unfair advantage over those who do not.

3. A campus-wide policy would help faculty members conform to a consistent policy on the matter.

4. Professors who explicitly or implicitly sanction student acquisition of instructor resources potentially create an unfair advantage for some students.

5. Allowing such purchases has the potential for adverse publicity - both for students and for their institutions.

4. Question: Refer back to Question 3, in which you are serving on a committee that is considering the ethics of student purchases of instructor resources on the Internet. The president asks you for the student view on this matter. List at least three justifications that your fellow students might give for using such a purchase to help them study. In addition, provide at least three objections that students might have to use such a purchase.

Answer: Arguments for a policy that allows students to use these resources include:

1. It's a free country.

2. Professors should be aware of the availability of test banks and solutions manuals on the Internet. Using them is therefore not unethical.

3. Some sororities and fraternities on campus maintain files of hard-copy tests from professors. Allowing students to purchase test-bank materials enables nonmembers to compete with them.

4. Such a policy encourages students to study.

5. Test-bank questions do not guarantee better grades - the professor might create his or her own questions on any given exam.

Arguments against a policy that allows students to use these resources include:

1. It may be illegal to sell these copyrighted materials. Students could consequently be buying stolen property.

2. Some students may not know about the availability of these materials and would consequently be at a disadvantage.

3. Students who are aware of the availability of these materials but who choose not to buy or use stolen property could be at a disadvantage.

4. Forbidding the use of test-bank resources encourages ethical behavior.

5. Forbidding the use of test-bank resources encourages students to actually learn the material. Is not that the purpose of a university education? 
5. Question: Discuss whether and how your answer to Question 4 would change if the resources were instructor-sanctioned (e.g., as an "optional" study guide that is available for the course text).

Answer: This would depend on whether the instructor has the permission of the publisher to make these resources available to students in the form of an optional study guide. Given that test-bank questions and solutions manuals are copyrighted materials, making these resources available in their entirety could potentially compromise the protection of such materials and could, therefore, be considered inappropriate. However, it is possible that some students might change their mind - e.g., because it's the professor's course and he or she makes the rules for it - and perhaps that the availability of these materials would benefit students as follows:

1. It encourages student studying.

2. Industrious students could be rewarded for their extra efforts.

3. The materials are available to all.

6. Question: Is buying a test bank on the Internet illegal? Why or why not? Answer: Yes, it is illegal. Students are freely choosing to look for, and purchase, stolen intellectual property, which is subject to widely known copyright laws and possibly trade secret laws. Students violate copyrights by downloading copyrighted test banks even when they do not know that the material is copyrighted.

7. Question: The article suggests several reasons why an instructor might be against the sale of instructional resources. Are there any arguments in favor of making instructional resources available to students as prescribed by publisher copyright restrictions (e.g., access on protected Web sites)? Why might an instructor permit, or even encourage, students to use test banks or solutions manuals? Give several reasons.

Answer: An instructor might be in favor of such sales to the extent that:

1. It encourages student studying.

2. Industrious students should be rewarded for their extra efforts.

3. The materials are available to all.

4. The teacher can still give a customized examination, using his or her own questions. 